\title{
CHARITÉ
}

\section{RIGHT VENTRICULAR INDEX OF MYOCARDIAL PERFORMANCE: COMPARISON OF TWO DIFFERENT TIME POINTS FOR EARLY PREDICTION OF BRONCHOPULMONARY DYSPLASIA}

\author{
Christoph Czernik, Ann-Katrin Minke, Boris Metze, Christoph Bührer \\ Department of Neonatology, Charité, Berlin, Germany
}

\section{BACKGROUND:}

Bronchopulmonary dysplasia (BPD) remains one of the most common and important morbidities in preterm infants. Previous studies have shown that the right ventricular index of myocardial performance (RIMP) is useful in predicting adverse respiratory outcome in these patients. The purpose of this study was to compare RIMP at two different time points for early prediction of BPD in very preterm infants.

\section{PATIENTS AND METHODS:}

Prospective echocardiography was performed in 51 preterm infants $<32$ weeks of gestation on day of life (DOL) 7 and 14, concomitant with urinary NTproBNP determination on DOL 7. Of these, 16 infants developed a BPD, as defined by need for supplemental oxygen at 36 postmenstrual weeks. Study population and patients groups characteristics are presented in Table 1 and 2. Measurement of RIMP parameters is shown in Figure 1.

\section{RESULTS:}

RIMP on DOL 7 and 14 was increased in infants with BPD (median [range] 0.34 [0.23-0.46] and 0.27 [0.02-1.1]), as compared to infants without BPD (0.2 [0.07-0.52] and 0.16 [0.03-0.45], $p<0.001)$. Similarly, NT-proBNP on DOL 7 was elevated in infants with BPD, as compared to controls (16695 (1254-35761) $\mathrm{pg} / \mathrm{ml}$ vs. 480 (62-30802) pg/ml; p<0.001) (Figure 2). AUCs for RIMP on DOL 7 (14) were $0.79(0.67)$ and 0.86 for NT-proBNP, respectively (Figure 3 ). The optimal cut-off value of RIMP $>0.3$ was on day 7 with a sensitivity of $79 \%$ and a specificity of $71 \%$ for predicting moderate or severe BPD with a high negative predictive value of $90 \%$.

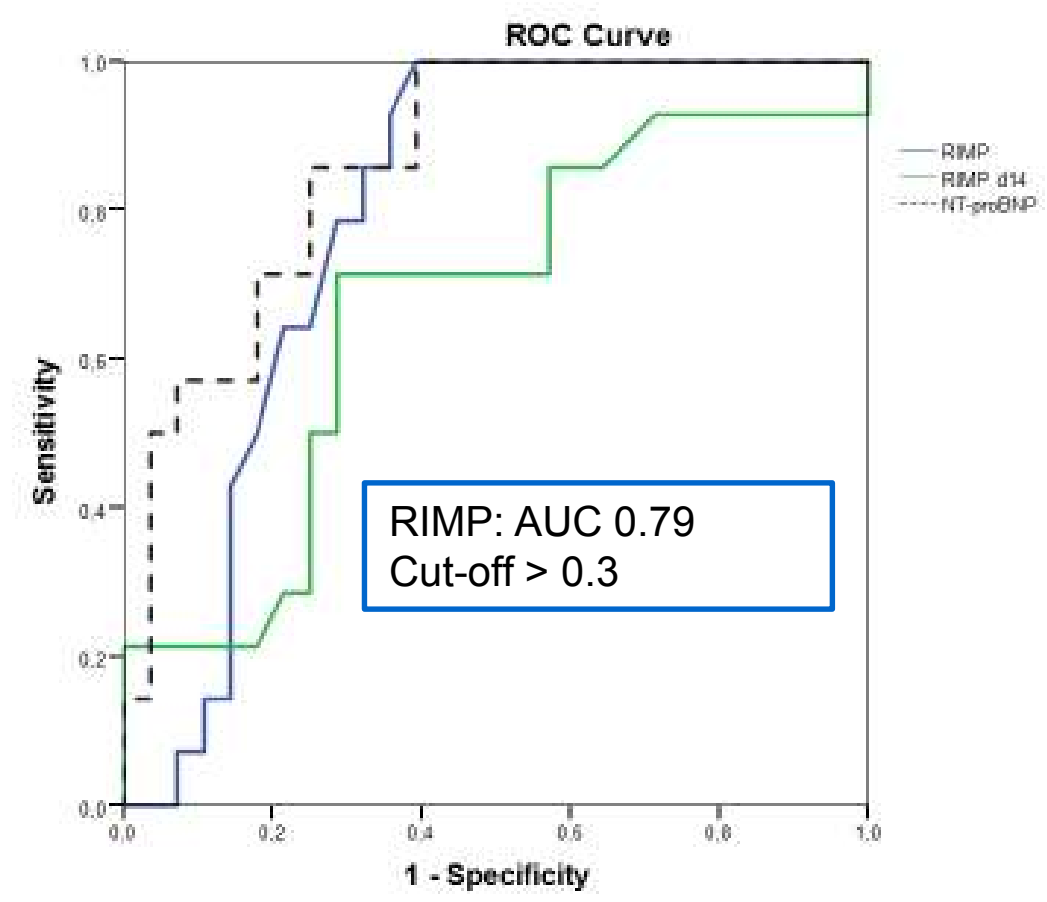

Figure 3: Receiver operating characteristic curve describing the ability of NT-proBNP on DOL 7 and RIMP on DOL 7 and 14 to predict a BPD in preterm infants $<32$ weeks.
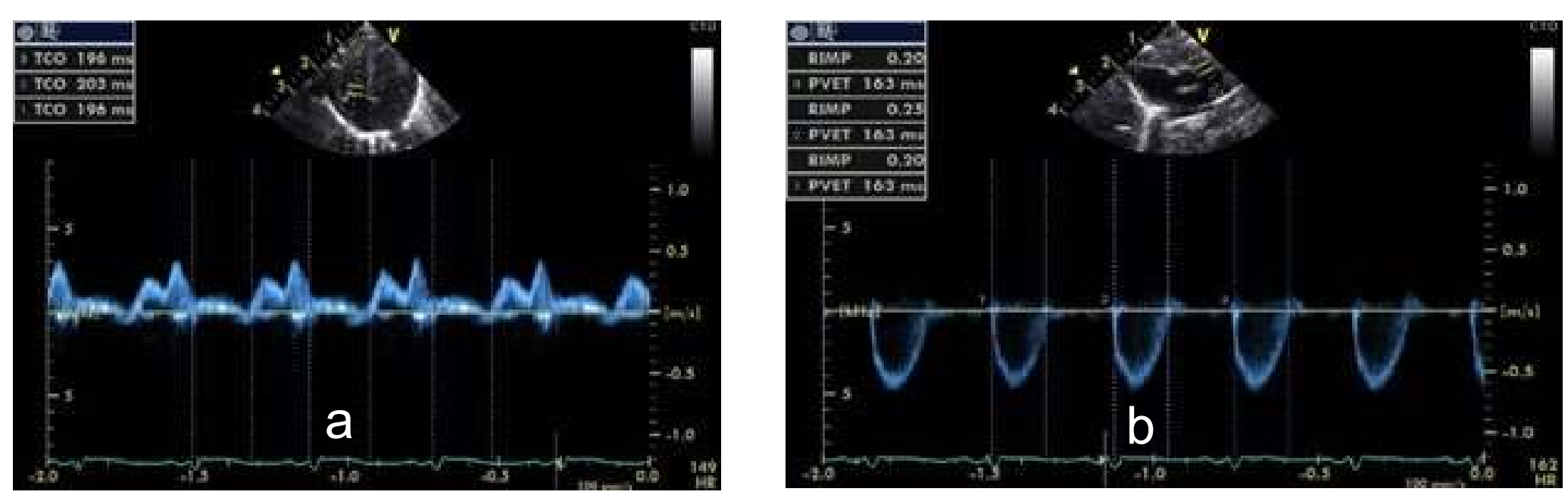

Figure 1: Doppler methodology. Measurement of RIMP parameters ((a-b)/b).

\begin{tabular}{|l|l|}
\hline Patients & $\mathrm{N}=51$ \\
\hline Gestational age (weeks) & $27(23-31)$ \\
\hline Birth weight (g) & $968(465-1880)$ \\
\hline Male n (\%) & $23(45)$ \\
\hline Fetal lung maturation n (\%) & $32(67)$ \\
\hline HsPDA n (\%) & $24(47)$ \\
\hline
\end{tabular}

Median (range)

Table 1: Study population

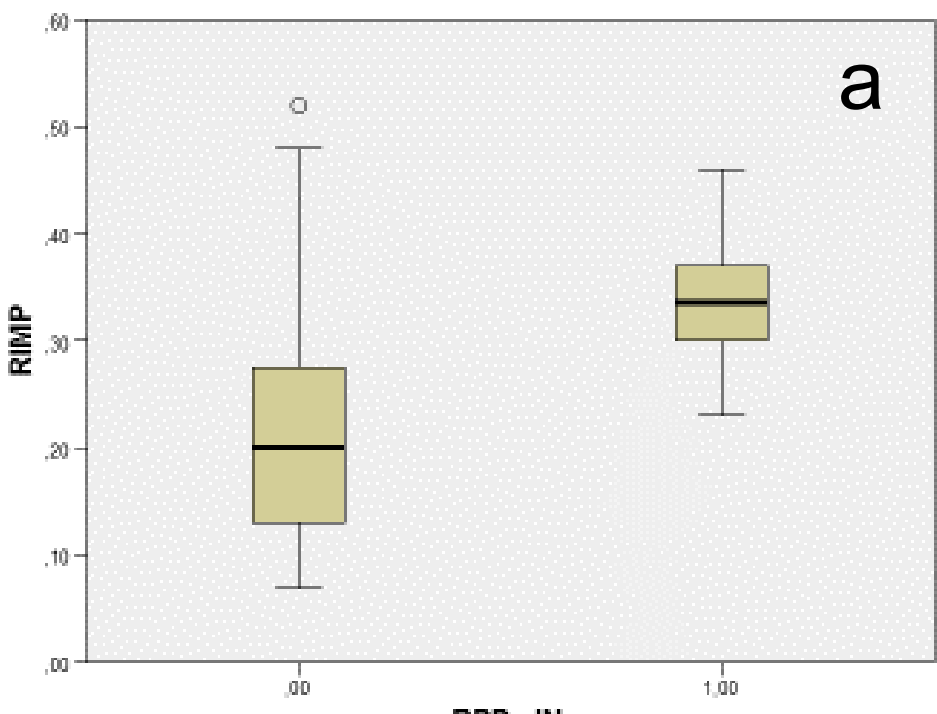

BPD JN

\begin{tabular}{|l|c|c|c|}
\hline & $\begin{array}{c}\text { Non BPD } \\
\mathrm{N}=35\end{array}$ & $\begin{array}{c}\mathrm{BPD} \\
\mathrm{N}=16\end{array}$ & $\mathrm{P}$ \\
\hline Gestational age (weeks) & $29(24-31)$ & $24(23-28)$ & $<\mathbf{0 . 0 1}$ \\
\hline Birth weight (g) & $\begin{array}{c}1175(465- \\
1880)\end{array}$ & $690(475-1100)$ & $<\mathbf{0 . 0 1}$ \\
\hline Male n (\%) & $14(40)$ & $9(56)$ & 0.37 \\
\hline Fetal lung maturation $\mathrm{n}(\%)$ & $23(70)$ & $9(60)$ & 0.53 \\
\hline $\begin{array}{l}\text { Surfactant administration } \mathrm{n} \\
(\%)\end{array}$ & $16(46)$ & $15(94)$ & $<\mathbf{0 . 0 1}$ \\
\hline Mechanical ventilation (days) & $0(0-61)$ & $33(0-97)$ & $<\mathbf{0 . 0 1}$ \\
\hline Death & 1 & 0 & \\
\hline
\end{tabular}

Table 2: Characteristics of the patients groups

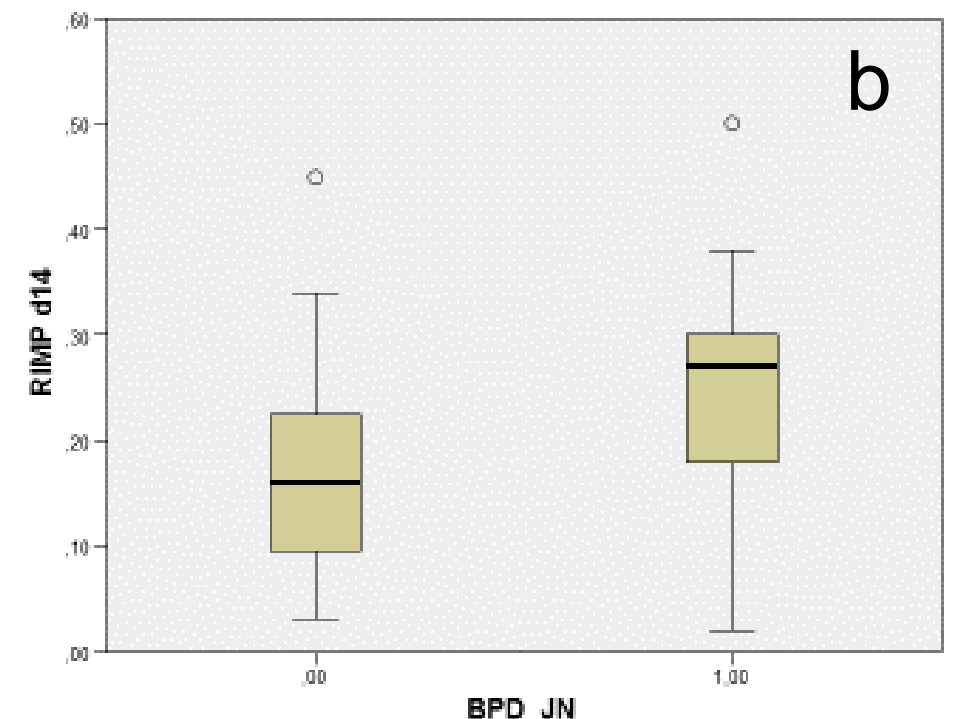

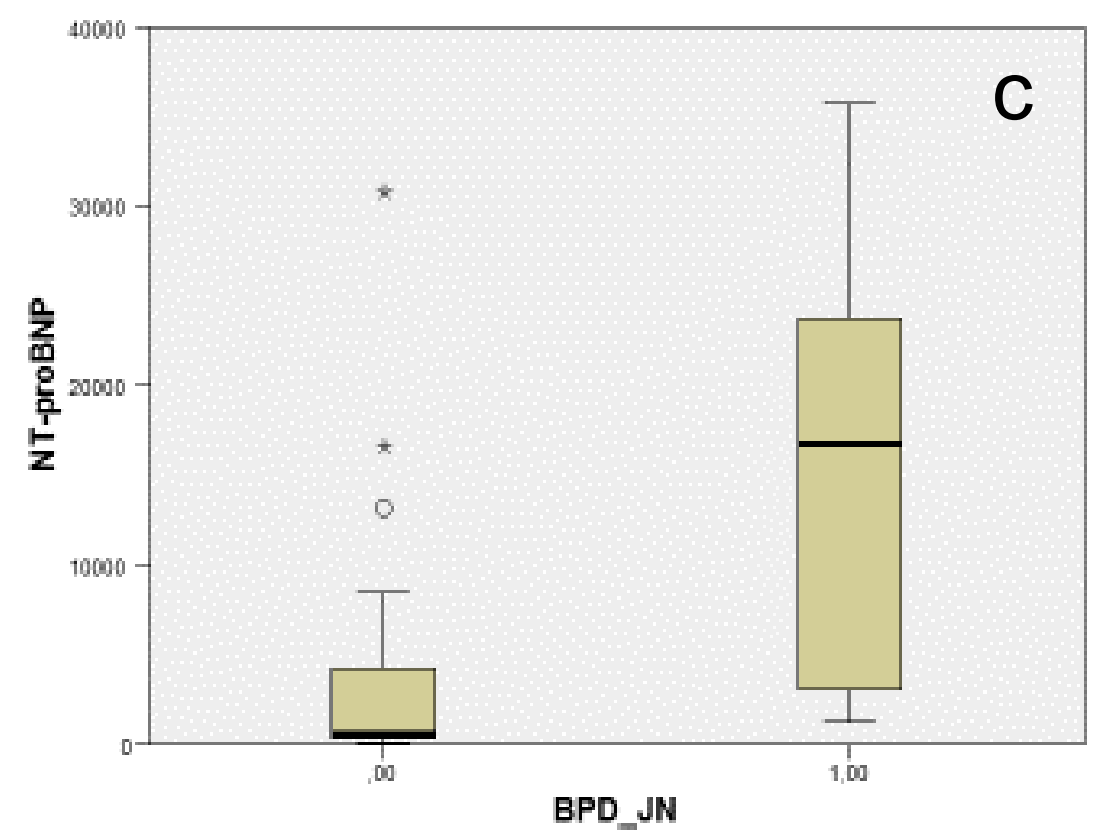

Figure 2: (a) RIMP on DOL 7 and (b) 14 and (c) NT-proBNP on DOL 7 in infants who did and infants who did not develop BPD.

\section{CONCLUSIONS:}

RIMP on DOL 7 is more suitable than on DOL 14 for early prognostic information in risk-stratification of preterm infants who subsequently develop BPD. 